\title{
TWIST1 Gene: First Insights in Felis catus
}

\author{
Cláudia S. Baptista ${ }^{1,2}$, Estela Bastos ${ }^{2}$, Sara Santos ${ }^{2}$, Ivo G. Gut ${ }^{3}$, Henrique Guedes-Pinto ${ }^{2}$, \\ Fátima Gärtner ${ }^{4,5}$ and Raquel Chaves*,2
}

\author{
${ }^{I}$ Department of Veterinary Clinics, Institute of Biomedical Sciences Abel Salazar (ICBAS), University of Porto, Largo \\ Prof. Abel Salazar, 2, 4099-003 Porto, Portugal \\ ${ }^{2}$ Institute for Biotechnology and Bioengineering, Centre of Genetics and Biotechnology, (IBB, CGB-UTAD), University \\ of Trás-os-Montes and Alto Douro, Quinta de Prados, 5001-801 Vila Real, Portugal \\ ${ }^{3}$ CEA/DSV/IG-Centre National de Génotypage, Bâtiment G2, 2 rue Gaston Crémieux, CP 5721, 91057 Evry Cedex, \\ France \\ ${ }^{4}$ Department of Pathology and Molecular Immunology, Institute of Biomedical Sciences Abel Salazar (ICBAS), Univer- \\ sity of Porto, Largo Prof. Abel Salazar, 2, 4099-003 Porto, Portugal \\ ${ }^{5}$ Institute of Pathology and Immunology (IPATIMUP), University of Porto, Rua Dr. Roberto Frias, s/n, 4200-465 Porto, \\ Portugal
}

\begin{abstract}
TWIST1 is thought to be a novel oncogene. Understanding the molecular mechanisms regulating the TWISTI gene expression profiles in tumor cells may give new insights regarding prognostic factors and novel therapeutic targets in veterinary oncology. In the present study we partially isolated the TWISTI gene in Felis catus and performed comparative studies. Several primer combinations were used based on the alignments of homologous DNA sequences. After PCR amplification, three bands were obtained, purified and sequenced. Several bioinformatic tools were utilized to carry out the comparative studies. Higher similarity was found between the isolated TWIST1 gene in Felis catus and Homo sapiens (86\%) than between Homo sapiens and Rattus norvegicus or Mus musculus (75\%). Partial amino acid sequence showed no change in the four species analyzed. This confirmed that coding sequences presented high similarity $(\sim 96 \%)$ between man and cat. These results give the first insights regarding the TWISTI gene in cat but further studies are required in order to establish, or not, its role in tumor formation and progression in veterinary oncology.
\end{abstract}

Received on: December 17, 2009 - Revised on: February 22, 2010 - Accepted on: February 24, 2010

Keywords: TWIST1 gene, Felis catus, comparative analysis, oncology.

\section{INTRODUCTION}

The TWIST1 gene was originally identified in Drosophila melanogaster where its activity was found to be crucial for the establishment of dorsoventral pattern and mesoderm formation of the embryo. This gene encodes a protein called Twist-1, a highly conserved transcription factor that belongs to the family of basic helix-loop-helix (bHLH) proteins [1$3]$.

In human, this gene (GenBank: NC_000007.13 and Ensembl: ENSG00000122691) has a length of $2188 \mathrm{bp}$ and is organized in two exons (1002 bp and $647 \mathrm{bp}$, respectively, exon 1 and exon 2) and one intron (539 bp). The first exon contains an open reading frame encoding a 202 amino acid protein (GenPept: AAC50930.1) being, currently, only one transcript characterized (GenBank: NM_000474 and Ensembl: ENST00000242261). In human, the TWIST1 gene maps to $7 \mathrm{p} 21.1$ and is expressed in the head and limb buds in

*Address correspondence to this author at the Institute for Biotechnology and Bioengineering, Centre of Genetics and Biotechnology, (IBB, CGBUTAD), University of Trás-os-Montes and Alto Douro, Quinta de Prados, 5001-801 Vila Real, Portugal; Tel: +351259350841; Fax: +351259350572; E-mail: rchaves@utad.pt developing embryos [4]. In adult human, its expression is predominantly detected in mesodermally derived tissues [5].

Several studies suggest that the TWIST1 gene is a novel oncogene that is associated with tumor formation and/or metastatic spread. In fact, besides the regulation of the embryonic morphogenesis, the Twist-1 protein has multiple functions during tumorigenesis, including inhibition of cell safeguard programs, altered cell-cell adhesion, and deregulation of differentiation, contributing to increased cell survival and invasion [5-9].

Mutations on the coding region of the human TWISTI gene, leading to haploinsufficiency, have been identified in Saethre-Chotzen syndrome (SCS) [10,11], in some cases of Baller-Gerold syndrome [12] and in human pediatric osteosarcomas [13]. Recently, Sahrin and colleagues [14] demonstrated an increased risk of breast cancer in women with Saethre-Chotzen syndrome, suggesting that germline mutations in TWISTI may also predispose to breast cancer.

TWIST1 overexpression was reported in a variety of solid cancers including breast, prostate and gastric carcinomas, melanomas, osteosarcomas, rhabdomyosarcomas, as well as in Sezary syndrome [6, 8, 13, 15-20]. 
Besides Drosophila and human, members of the TWIST family have also been identified in different species such as frog [21], mouse [22], leech [23], zebrafish [24], lancelet [25], nematode [26], jellyfish [27] and chicken [28]. To the best of our knowledge, this gene has never been described in Felis catus.

In the present work we achieved the partial isolation of TWIST1 gene in cat. As far as we know, TWIST1 has never been previously isolated in cat. We accomplish this purpose in order to carry out comparative studies between Felis catus and other species, namely Homo sapiens, and to perform in silico mapping of this gene in cat. We present a new approach than can be used to in silico gene map, and that use several tools that result from the cat and canine genomes sequencing efforts, that is, sequence data and radiation hybrid maps. We believe that this knowledge is a starting point that may permit the research of the molecular mechanisms regulating $T W I S T 1$ gene expression in veterinary oncology.

\section{MATERIAL AND METHODS}

\section{Genomic DNA Extraction and PCR Amplification}

Blood samples from six different cats were used as the biological material for DNA extraction. After owners consent, blood was collected by venipuncture and stored in tubes with heparin as anticoagulant. DNA extraction was performed from $200 \mu \mathrm{L}$ of total blood using automatic equipment (Quickgene-810, Fujifilm), and the Quickgene Whole Blood Kit S (Fujifilm) according to instructions of the manufacturer. In order to analyze the integrity of the genomic DNA extracted all samples were subjected to a $1.5 \%$ agarose gel electrophoresis. The quantity and quality of the DNA extracted was also determined in a NanoDrop ND-1000 spectrophotometer (NanoDrop Technologies).

In order to isolate the TWISTI gene from Felis catus genomic DNA, primers were designed based on the alignments of homologous DNA sequences, from species where this gene was already identified, Homo sapiens (GenBank NC 000007.12) and Canis familiaris (GenBank NC 006596.2).

The different primer combinations and corresponding sequences are shown in Table 1. For combination 1, DNA was amplified after $95^{\circ} \mathrm{C}$ denaturation for 5 min with $35 \mathrm{cy}$ cles of $95^{\circ} \mathrm{C}$ for $30 \mathrm{~s}, 65^{\circ} \mathrm{C}$ for $30 \mathrm{~s}, 72^{\circ} \mathrm{C}$ for $30 \mathrm{~s}$ and a $72^{\circ} \mathrm{C}$ final extension step for $10 \mathrm{~min}$. The $25 \mu \mathrm{L}$ PCR reaction mix contained: $1.5 \mu \mathrm{L}$ each primer $(100 \mathrm{ng} / \mu \mathrm{L}), 1.5 \mu \mathrm{L} \mathrm{MgCl}_{2}$ at $25 \mathrm{mM}, 2 \mu \mathrm{L}$ dNTP mix $(2.5 \mathrm{mM}), 2 \mu \mathrm{L}$ DNA $(78 \mathrm{ng} / \mu \mathrm{L})$, $0.5 \mu \mathrm{L}(5 \mathrm{U} / \mu \mathrm{L})$ Taq DNA polymerase (Fermentas), $2.5 \mu \mathrm{L}$ buffer and $13.5 \mu \mathrm{L}$ water. For primers combination $\mathbf{2}$ and $\mathbf{3}$, the PCR temperature cycle conditions and concentrations were identical to $\mathbf{1}$ except for the annealing temperature which was $60^{\circ} \mathrm{C}$ instead of $65^{\circ} \mathrm{C}$.

All the amplifications were performed on a T-Personal Thermal Cycler (Biometra) and the PCR products were analyzed by electrophoresis in $1.5 \%$ agarose gel, stained with ethidium bromide, visualized under UV light and digitally recorded (UviDoc).

The PCR fragments were excised from the agarose gel and purified, according to the procedure described by Geneclean II Brief Protocol: Purifying DNA (QBiogene).

\section{RNA Extraction and RT-PCR Amplification}

Necropsy of a cat with several traumatic lesions due to a car accident was immediately performed after euthanasia for fresh tissue sampling. Other than the skull and cervical vertebral column, no significant internal lesions were observed. Macroscopically normal tissue samples such as skin, liver, spleen, lung, kidney, testicles and bone marrow were stored $\left(-80^{\circ} \mathrm{C}\right)$ in a RNA stabilization solution (RNA Later Tissue Collection, Ambion). Total RNA was extracted with the standard Trizol method (Invitrogen) and quantified by spectrophotometry using the NanoDrop ND-1000 (NanoDrop Technologies). The total reaction volume for cDNA synthesis and amplification (one step reaction) was $20 \mu \mathrm{L}$ including: $1 \mu \mathrm{L}$ of RNA extracted from testicles $(1 \mu \mathrm{g} / \mu \mathrm{L}), 8 \mu \mathrm{L}$ of the One-step RT-PCR pre-mix (Intron), $1 \mu \mathrm{L}$ of each primer (5' GAGCCCGCAGTCGTACGAG 3', and 5' CTCTGGA GGACCTGGTAGAGGA 3'; $100 \mathrm{ng} / \mu \mathrm{L}$ ) and $9 \mu \mathrm{L}$ of water. cDNA was amplified after reverse transcription at $45^{\circ} \mathrm{C}$ for $30 \mathrm{~min}, 94^{\circ} \mathrm{C}$ denaturation for 5 min with 29 cycles of $94^{\circ} \mathrm{C}$ for $30 \mathrm{~s}, 57^{\circ} \mathrm{C}$ for $30 \mathrm{~s}, 72^{\circ} \mathrm{C}$ for $30 \mathrm{~s}$, with a $72^{\circ} \mathrm{C}$ final extension step for $5 \mathrm{~min}$. This amplification was performed on a T-Personal Thermal Cycler (Biometra) and the RT-PCR product was analyzed in a $1.5 \%$ agarose gels stained with ethidium bromide and visualized with an ultraviolet transilluminator UviDoc.

The cDNA was excised from the agarose gel and purified with the Geneclean II Brief Protocol: Purifying DNA kit (QBiogene).

\section{Sequencing of the Amplified Products}

PCR samples were sequenced in both directions and sequence analysis was performed using the bioinformatic resource at the NCBI: Basic Local Alignment Search Tool

Table 1. Primer Combinations Used for the DNA Isolation of Felis catus TWIST1 Gene

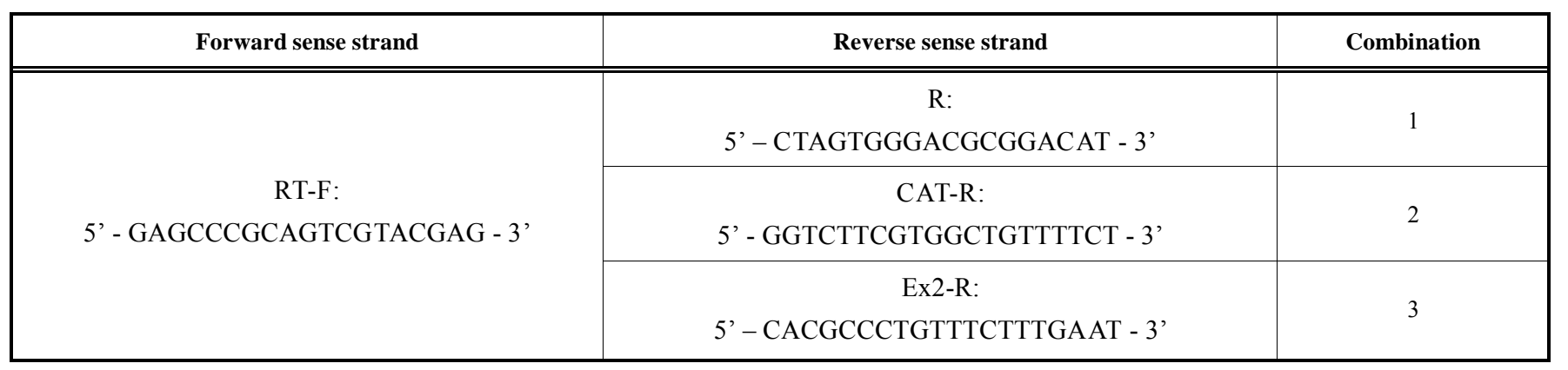


(BLAST) and the Vector NTI software (Invitrogen Life Technologies). The feline TWIST1 DNA sequence and the TWIST1 cDNA sequence have been submitted to GenBank with the respectively accession number GQ167299 and GQ167300.

\section{Phylogenetic Analysis}

For the phylogenetic and evolutionary analysis of the molecular sequence data we used Phylemon [29], an online platform that integrates a suite of more than 20 different tools.

The largest sequenced fragment $(960 \mathrm{bp}$ ) (fragment 3 from Table 1) was aligned with TWIST1 gene from Homo sapiens (GenBank NC_000007.12), Macaca mulatta (GenBank NC 007860.1), Pan troglodytes (Ensemble release 47: ENSPTRG $\bar{G} 00000018960$, Contig 5.948 and Contig 5.949), Mus musculus (GenBank NC_000078.5), Rattus norvegicus (GenBank NC_005105.2), Bos Taurus (GenBank NC 007302.2) and Gallus gallus as the outgroup species (Ensemble release 47: ENSGALT00000010219, Contig 16422).

We utilized the ClustalW v1.83 program [30] for the alignment of the previously mentioned multiple sequences. Basic maximum likelihood (ML) analyses of the DNA sequence data were provided with the DnaML algorithm of the PHYLIP package (version 3.65). Details of the algorithm are published in the paper by Felsenstein and Churchill [31].

In order to confirm the phylogram we used the MEGA4 program [32] that utilizes Maximum Composite Likelihood (MCL) method for estimating evolutionary distances between DNA sequences. The phylogeny reconstruction analysis was performed with the Neighbor-Joining method and the Nucleotide: Maximum Composite Likelihood substitution model.

\section{Protein Prediction}

For protein prediction of the $960 \mathrm{bp}$ fragment of TWIST1 gene, we used the tool TranSeq from EMBOSS (European Molecular Biology Open Software Suite) [33]. This tool translates nucleic acid sequences to the corresponding peptide sequence. We used frame 2 after analysing the six possible reading frames. Simultaneously, in order to confirm the result, we used multiple alignments of the eight sequences performed by the ClustalW program, described on the previous section. We converted the multiple alignment into the multi sequence format (msf) used by GenDoc program, a multiple sequence alignment editor developed by Nicholas et al. [34]. The protein prediction was confirmed on the Genedoc program allowing to simultaneously edit the aligned sequences and execute the translation of the coding region into the amino acid sequence.

\section{Gene Localization}

The TWIST1 gene was in silico physically mapped in Felis catus. In order to perform a comparative analysis we also mapped this gene in the following species: Homo sapiens, Pan troglodytes, Macaca mulatta, Bos taurus, Gallus gallus, Mus musculus, Rattus norvegicus and Canis familiaris.
The in silico analysis of the largest sequenced fragment (960 bp), partial sequence of the TWIST1 gene, was primarily performed using the "MultiBlast Analysis" (ENSEMBL Genome Browser). All the results obtained were confirmed using the "SyntenyView" (ENSEMBL Genome Browser). Since the cat karyotype is not available in the ENSEMBL Genome Browser, the physical map of this gene was established with the Genome Browser for Felis catus, the Genome Annotation Resource Fields - GARFIELD [35], the initial sequence and comparative analysis of the cat genome published by Pontius et al. [36], and the radiation hybrid maps from Murphy et al. [37] and Davis et al. [38]. We also used the dog map information in order to improve the localization of the TWIST1 gene in the cat chromosome. We used the 4249 marker FISH/RH map of the canine genome for chromosome 14 from Breen et al. [39] and the FISH/RH maps available from the same author at http://cvm.ncsu.edu/mbs/ breen/dog_map.htm.

The genome versions used in ENSEMBL Genome Browser were: Homo sapiens (NCBI36), Pan troglodytes (CHIMP2.1), Macaca mulatta (MMUL1.0), Bos taurus (BTAU_4.0), Gallus gallus (WASHUC2), Mus musculus (NCBI m37), Rattus norvegicus (RGSC 3.4), Canis familiaris (CanFam2.0) and Felis catus (CAT).

\section{RESULTS}

\section{Genomic DNA Extraction and PCR Amplification}

The DNA samples obtained from $200 \mu$ of blood using Quickgene Whole Blood Kit S (Fujifilm) showed a satisfactory concentration (between $67.66 \mathrm{ng} / \mu \mathrm{L}$ and $88.57 \mathrm{ng} / \mu \mathrm{L}$, with a total yield of $200 \mu \mathrm{L}$ ). The DNA integrity evaluated by agarose gel electrophoresis and by spectrophotometry was satisfactory $\left(\mathrm{OD}_{260} / \mathrm{OD}_{280}=1.91\right)$.

In order to amplify the TWIST1 gene from cat genomic DNA extracted from 6 blood samples, we synthesized multiple primers based on the homologous sequences from Homo sapiens (GenBank NC_000007.12) and Canis familiaris (GenBank NC_006596.2). To successfully achieve this goal several primers combinations were used (Table 1) and, for each sample, the obtained fragments have, approximately, the following lengths: $\mathbf{1}=300 \mathrm{bp} ; \mathbf{2}=800 \mathrm{bp}$ and $\mathbf{3}=1000 \mathrm{bp}$ (Fig. 1a, 1c).

\section{RNA Extraction and RT-PCR Amplification}

To verify if the TWIST1 gene in Felis catus was a coding gene and, if so, in order to localize the coding region, we performed reverse-transcriptase PCR amplification. Total RNA extracted from testicles, liver and bone marrow with the standard Trizol method (Invitrogen) presented a good quantity $(281.5 \mathrm{ng} / \mu \mathrm{L}, 189 \mathrm{ng} / \mu \mathrm{L}$ and $210.5 \mathrm{ng} / \mu \mathrm{L}$ respectively) and quality evaluated by spectrophotometry $\left(\mathrm{OD}_{260} / \mathrm{OD}_{280}=1.86,1.87\right.$ and 1.83 , respectively $)$. Using primers 5'-GAGCCCGCAGTCGTACGAG-3' and 5'CTCTGGAGGACCTGGTAGAGGA-3', designed based in homologous sequences from Homo sapiens (GenBank $\mathrm{NC}$ 000007.12) and Canis familiaris (GenBank NC_006596.2), in each sample, we amplified a fragment with around $200 \mathrm{bp}$ (Fig. 1b). 


\section{Sequencing of the Amplified Products}

After PCR amplification using the multiple primers combinations evidenced in Table $\mathbf{1}$ and Figs. (1a and 1c), the obtained fragments were excised from the agarose gel, purified and directly sequenced in both directions. After thorough analysis of the 36 sequencing reactions, we isolated $960 \mathrm{bp}$ of the feline TWIST1 gene DNA. This sequence is shown in Supplementary Fig. (1), where it is aligned with the human sequence. Strong similarity $(86 \%)$ was found between the human sequence and the amplified feline DNA. We can observe major differences in the intron, whereas exon 1 and exon 2 are highly conserved.

To analyze mRNA encoded by the TWIST1 gene, primers were designed on the feline DNA putative coding region, identified on the basis of similarity between the feline (Supplementary Fig. 1) and the human DNA sequence. cDNA was obtained from retro-transcription of total RNA isolated from cat testicle. This amplification, allowed us to isolate a fragment with around $200 \mathrm{bp}$ which was also excised from an agarose gel, purified and sequenced in both directions. After sequence evaluation, the resulting $201 \mathrm{bp}$ of feline cDNA was subject to BLAST analysis. The information confirmed that we isolated the cat TWIST1 gene cDNA. Using the ClustalW program, we aligned this sequence (Supplementary Fig. 1, underline 201 bp sequence) with the partially isolated predicted coding region (Supplementary Fig. 1, blue $316 \mathrm{bp}$ sequence) and we concluded that the isolated cDNA is $100 \%$ included in the predicted coding region of the Felis catus TWIST1 gene.

\section{Phylogenetic Analysis}

The $960 \mathrm{bp}$ sequence from cat TWISTI gene was aligned with homologous sequences from Homo sapiens, Macaca mulatta, Pan troglodytes, Mus musculus, Rattus norvegicus, Bos taurus and Gallus gallus in order to obtain the phylogram presented in Fig. (2). The results displayed by the phylogenetic analysis allowed us to conclude that there is a higher similarity between the homologous sequences from Homo sapiens and Felis catus (86\%) than similarity between Homo sapiens and Rattus norvegicus or Mus musculus $(75 \%)$. We also found a high similarity $(96 \%)$ between Homo sapiens and Felis catus regarding the 316 bp (partial exon 1) fragment. In fact, we detected a higher similarity between cat and man for the sequence analyzed when comparing with other animal models, as the classical rat and mouse.

\section{Protein Prediction}

The deduced partial amino acid sequence of the Twist-1 protein in all species analyzed was generated by the Genedoc program, starting from the Phylemon platform. The maximal length of the partial coding region isolated from cat genomic DNA has 316 bp (Fig. 1c and Table 1, primer combination 1) and 104 deduced amino acids from a predicted total of 202 amino acids. The results displayed were confirmed comparing our amino acid sequence with known amino acid sequences from GenBank database, from Homo sapiens (GenBank NC_000007.12), Rattus norvegicus (GenBank NC_005105.2), Mus musculus (GenBank NC_000078.5),

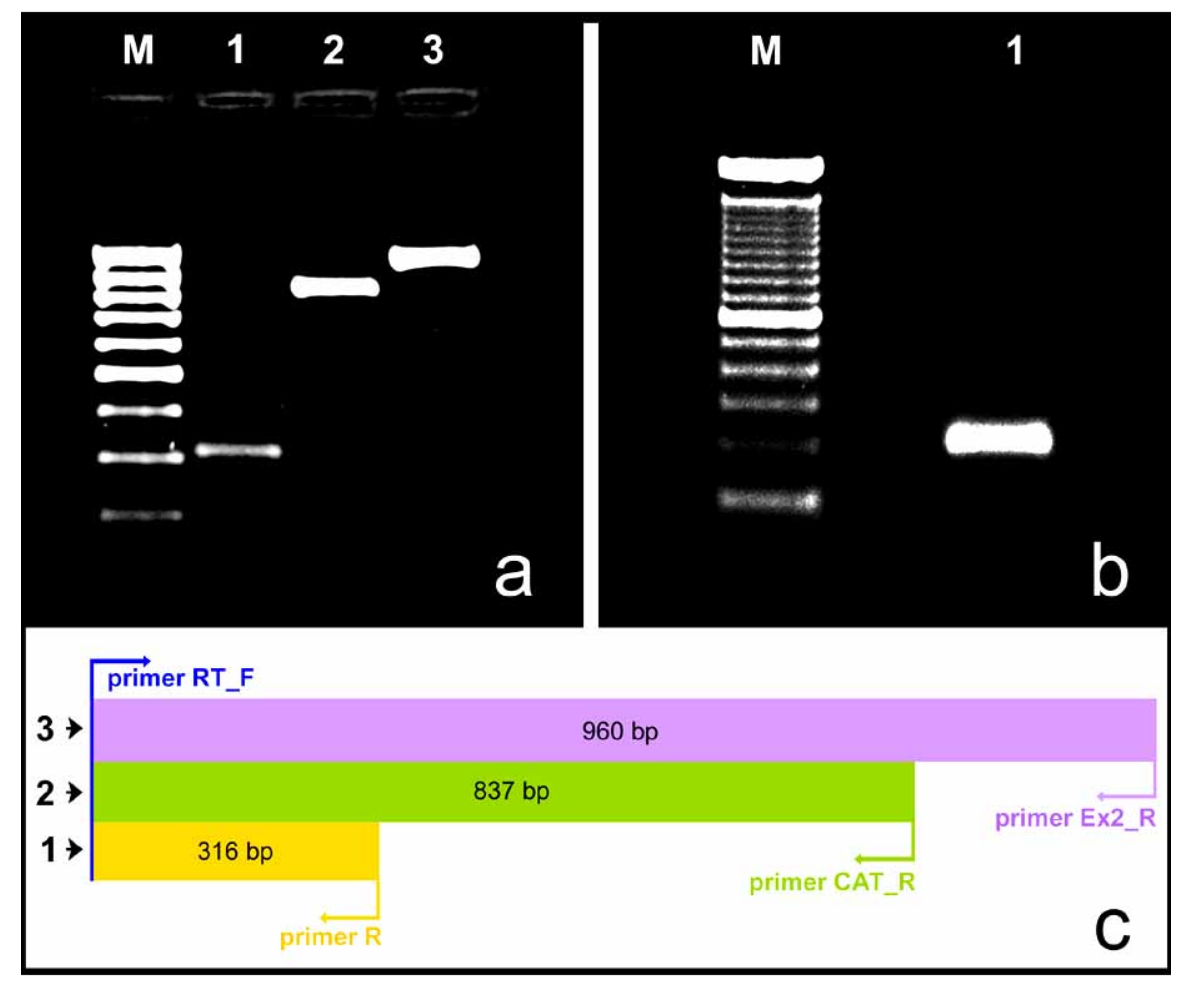

Fig. (1). (a) Electrophoresis of the PCR products obtained from cat gDNA extracted from $200 \mu$ of blood in a 1.5\% agarose gel. Three bands of different sizes were obtained. Lane M: Molecular marker (Gene Ruler 100 bp DNA Ladder, Fermentas). Lanes 1-3: Amplified products with approximately 300, 800 and $1000 \mathrm{bp}$; (b) Electrophoresis of the RT-PCR product in a 1.5\% agarose gel. Lane M: Molecular marker (Mass Ruler DNA Ladder Mix, Fermentas). Lane 1: RT-PCR fragment with approximately $200 \mathrm{bp}$. (c) Scheme for the sequencing of Felis catus TWIST1 gene with the identification and localization of primers and the respective product length. 


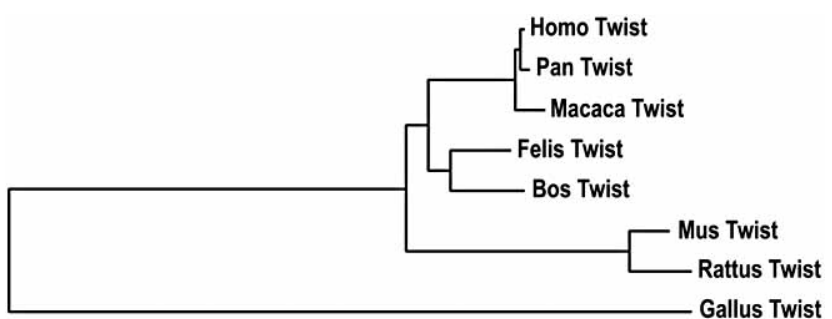

0.05

Fig. (2). Phylogram constructed using the alignment between the isolated $960 \mathrm{bp}$ sequence from cat TWIST1 gene and homologous sequences from Homo sapiens, Macaca mulatta, Pan troglodytes, Mus musculus, Rattus norvegicus, Bos taurus and Gallus gallus.

Macaca mulatta (GenBank NC_007860.1), Pan troglodytes (Ensemble release 47: ENSPTRG00000018960, Contig 5.948 and Contig 5.949), Bos Taurus (GenBank NC_007302.2) and Gallus gallus (Ensemble release 47: ENSGALT00000010219, Contig 16422). The multiple alignments were performed by the ClustalW program (Fig. 3) and they show no change in all the species analyzed, except for Gallus gallus (the outgroup species) where 13 amino acids were modified. Between Homo sapiens and Felis catus we detected 8 transitions and 2 transversions meaning that the conservation at the protein level is different from the scenario observed at the genomic level.

\section{Gene Localization}

The results regarding the in silico physical mapping of the TWIST1 gene in Felis catus, Canis familiaris, Homo sapiens, Pan troglodytes, Macaca mulatta, Mus musculus, Rattus norvegicus, Bos taurus and Gallus gallus species are presented in Fig. (4).
The in silico analysis of the largest sequenced DNA fragment from the cat TWIST1 gene (i.e. 960 bp DNA fragment) was blasted on the genomes from the species in analysis, using the "MultiBlast Analysis" tool from the ENSEMBL Genome Browser. This analysis allowed the physical mapping of the cat TWIST1 partial sequence on the following chromosome (chr) species (Fig. 4c): Canis familiaris chr 14, Homo sapiens chr 7p21.1, Pan troglodytes chr 7, Macaca mulatta chr 3, Mus musculus chr 12B2, Rattus norvegicus chr 6q16 and Bos taurus chr 4. Moreover, in all analysis, and for each chromosome, it was possible to determine the localization of the predicted gene in terms of $\mathrm{Mb}$ with a higher precision (Fig. 4c). All the results obtained were confirmed using the "Synteny View" tool from the ENSEMBL Genome Browser what allows the search of the syntenic segments between these genomes (Fig. 4c). The TWIST1 gene was mapped to chr 2 in Gallus gallus; however, this analysis was only possible through the physical mapping of the cat TWIST1 gene made in the human genome using the "view synteny regions" tool in the "contigview" menu. Therefore, the localization of the predicted gene in terms of $\mathrm{Mb}$ in this chromosome was not as accurate (see Fig. 4c) as for the other genomes.

Finally, the cat TWIST1 gene was physically mapped to chr A2 (q21.3) in the cat karyotype (Fig. 4b). In this case we used the Genome Browser for Felis catus, the Genome Annotation Resource Fields - GARFIELD [35], the initial sequence and comparative analysis of the cat genome published by Pontius et al. [36], and the radiation hybrid maps from Murphy et al. [37] and Davis et al. [38]. The simple search of the TWIST1 gene in the cat genome showed the chromosome A2 involved (see Fig. 4b), with the fine localization in terms of $\mathrm{Mb}$ on this chromosome. However, this analysis does not permit to physically map the gene in the A2 ideogram (physical mapping at band level). In order to accomplish this task, we used the cat radiation hybrid maps

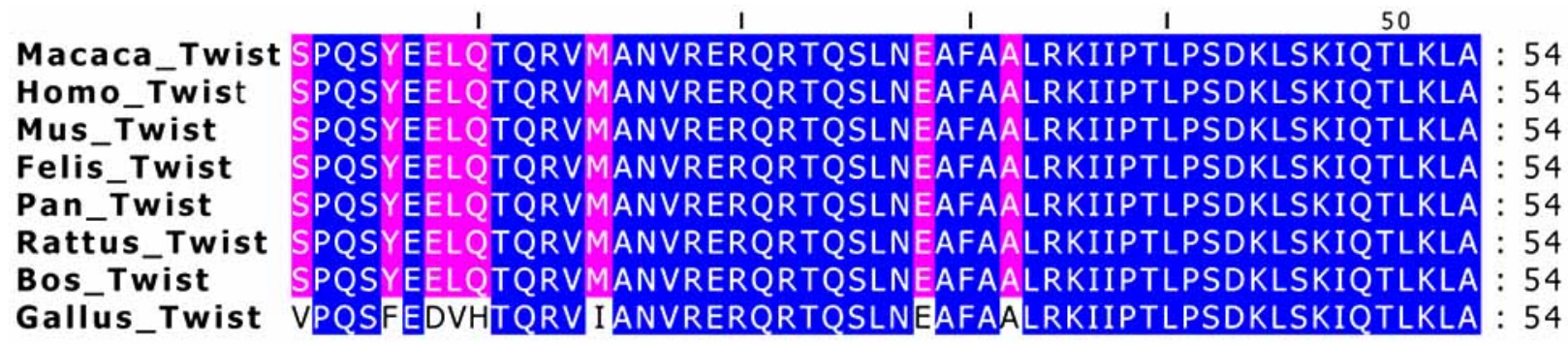

\begin{tabular}{lll} 
& \multicolumn{1}{c}{ I } & 1 \\
Macaca_Twist & ARYIDFLYQVLQSDELDSKMASCSYVAHERLSYAFSVWRMEGAWSMSASH $: 104$ \\
Homo_Twist & ARYIDFLYQVLQSDELDSKMASCSYVAHERLSYAFSVWRMEGAWSMSASH $: 104$ \\
Mus_Twist & ARYIDFLYQVLQSDELDSKMASCSYVAHERLSYAFSVWRMEGAWSMSASH : 104 \\
Felis_Twist & ARYIDFLYQVLQSDELDSKMASCSYVAHERLSYAFSVWRMEGAWSMSASH : 104 \\
Pan_Twist & ARYIDFLYQVLQSDELDSKMASCSYVAHERLSYAFSVWRMEGAWSMSASH: 104 \\
Rattus_Twist & ARYIDFLYQVLQSDELDSKMASCSYVAHERLSYAFSVWRMEGAWSMSASH : 104 \\
Bos_Twist & ARYIDFLYQVLQSDELDSKMASCSYVAHERLSYAFSVWRMEGAWSMSASH : 104 \\
Gallus_Twist & ARYIDFLYQVLQSDELDHKITSCNYLAHERLSYAFSVWRMEGAWSMSASH : 104
\end{tabular}

Fig. (3). For all species analyzed (Homo sapiens, Rattus norvegicus, Mus musculus, Macaca mulatta, Pan troglodytes, Bos Taurus and Gallus gallus) the partial amino acid sequence of the Twist-1 protein was deduced using the Genedoc program, starting from the Phylemon platform, and the multiple alignments were performed using the ClustalW program. We can observe 104 amino acids (316 bp of the coding region isolated in cat) from a predicted total of 202 amino acids (coding region with 609 bp). Only the outgroup species (Gallus gallus) evidences 13 different amino acids. 


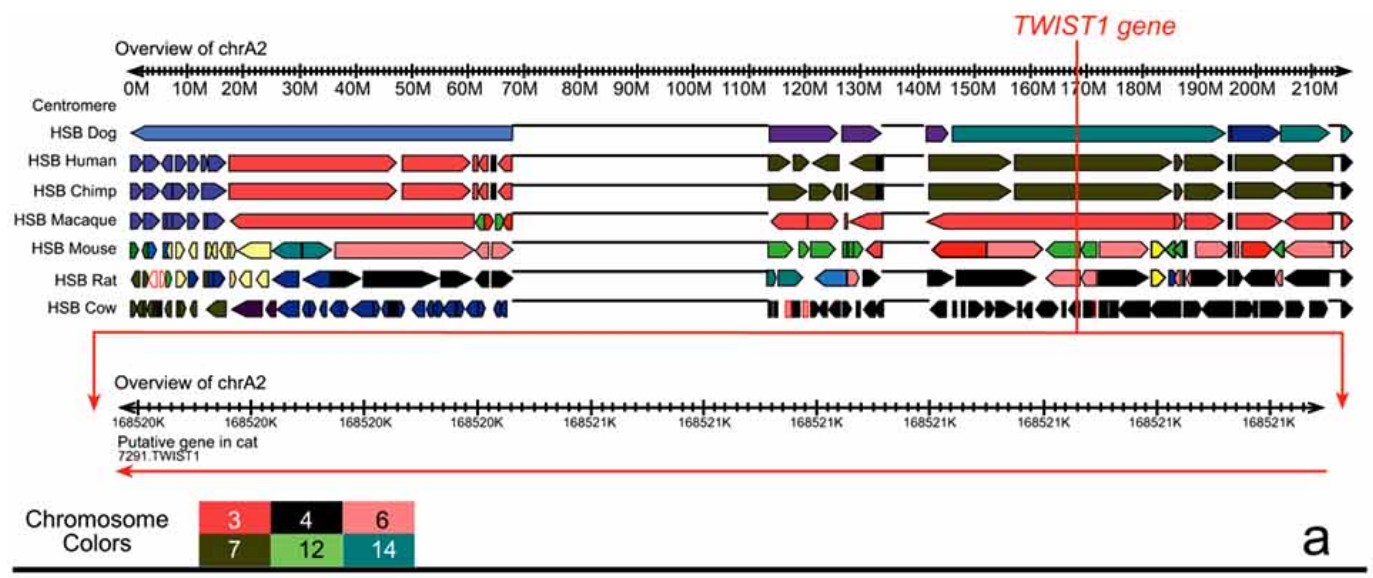

chrA2
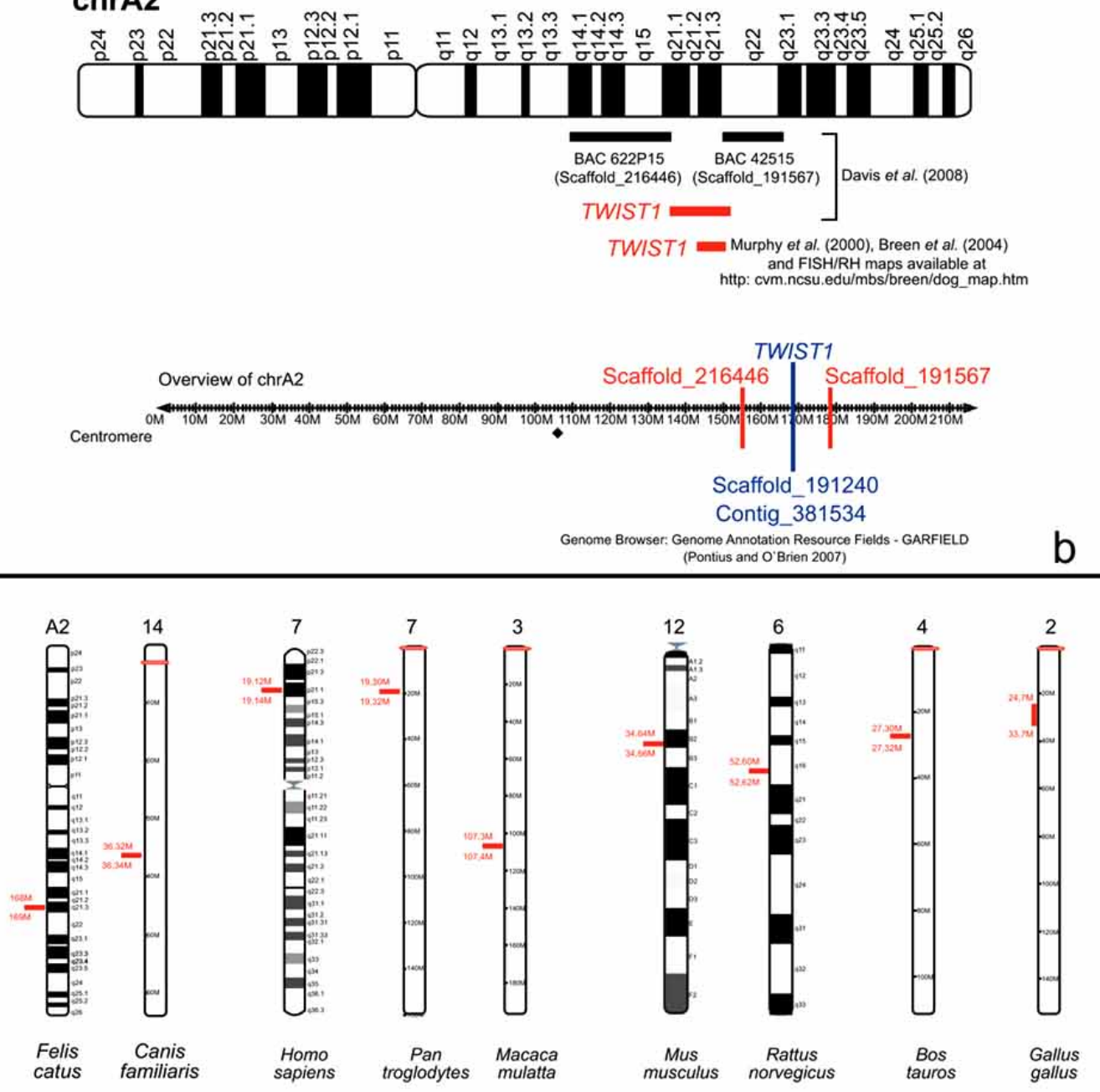

C

Fig. (4). Physical mapping of the TWIST1 gene in Felis catus, Canis familiaris Homo sapiens, Pan troglodytes, Macaca mulatta, Mus musculus, Rattus norvegicus, Bos taurus and Gallus gallus species. (a) In silico comparative analysis of the TWIST1 gene with the Genome Annotation Resource Fields - GARFIELD [35]. (b) The in silico physical map of this gene was established with the Genome Browser for Felis catus, the Genome Annotation Resource Fields - GARFIELD [35], the initial sequence and comparative analysis of the cat genome published by Pontius et al. [36], and the radiation hybrid maps from Murphy et al. [37] and Davis et al. [38]. We also used the dog map information in order to improve the localization of the TWIST1 gene in the cat chromosome. We used the 4249 marker FISH/RH map of the canine genome for chromosome 14 from Breen et al. [39] and the FISH/RH maps available from the same author at http://cvm.ncsu.edu/mbs/breen/dog_map.htm. (c) Chromosome ideograms showing the TWIST1 gene localization in several species analysed in the present work. 
[37-38] and the 4249 marker FISH/RH map of the canine genome for the 14 chromosome [39] and the FISH/RH maps available at http://cvm.ncsu.edu/mbs/breen/dog_map.htm. With this comparative analysis it was possible to in silico map the TWIST1 gene to the q21.3 band from cat chromosome A2 (Fig. 4c).

\section{DISCUSSION}

It is commonly accepted that naturally occurring cancers in dogs and cats offer a unique opportunity as models for human cancer biology and translational cancer therapeutics. Several aspects contribute to the advantages of the companion animal model such as the relatively high incidence of some cancers when compared with humans, similar biological behavior with faster rate of progression, large body size that allow imaging studies as well as surgical interventions, comparable responses to cytotoxic agents and radiation therapy, shorter overall lifespan and similar environmental risk factors. It is also important to consider that animal trials are generally much more economical to run than human trials [40-42]. In this work we present evidence that TWIST1 may be targeted in new studies to understand its role in feline oncology and that, potentially, Felis catus could be a very interesting animal model to study human disease, at least regarding this gene.

To the best of our knowledge, TWIST1 has never been previously isolated in cat. Therefore, in order to accomplish this purpose and perform comparative studies, several primer combinations were designed to successfully obtain the partial amplification of the TWIST1 gene in this species. The segments of interest had a high GC content making this task somewhat challenging, but we were able to successfully isolate $960 \mathrm{bp}$ of the cat TWIST1 gene, namely $358 \mathrm{bp}$ of the exon 1 (including $316 \mathrm{bp}$ of the coding region), $516 \mathrm{bp}$ of the intron and 86 bp of the exon 2 (Fig. 5). When compared to the homologous sequence in Homo sapiens, this isolated sequence presented major genomic differences in the nonconserved intronic region, as expected (80\% similarity). Evolutionarily conserved regions, meaning exon 1 and exon 2 , evidenced $96 \%$ similarity between both these species.

According to the ENSEMBL Genome Browser latest release 57 (March 2010), in cat, the homologous region with respect to the human TWIST1 gene predicts a novel pseu- dogene (ENSFCAG00000006288). These genes are defined as genomic DNA sequences that bear significant homology to functional genes but have lost their potential as DNA templates for functional products $[43,44]$. However, in this research work, the RT-PCR results demonstrated that the feline TWIST1 gene is a transcribed gene, evidencing, at least, one transcript. However, additional studies are required in order to study its expression profile in normal and tumor cells, in this species.

The phylogenetic analysis performed with the alignment of largest cat DNA fragment from TWIST1 gene and homologous sequences from several species (Fig. 2), detected a higher similarity between the sequences of cat and man. This information is extremely important, suggesting the cat as an attractive model, at least for TWIST1 gene studies, and that should be used instead of the classical animal models (e.g. the rat and mice). This data is supporting a growing body of evidence that propose alternative animal models, as the cat, relative to the classical ones. In fact, the evolutionary history of the genomes indicates great conservation between cat and human, with around 30 homologous segments separating both genomes. In contrast, genomes as the ones of rat, mouse and dog are four times more reshuffled than those of species retaining the more slowly evolving genomes (e.g. cat and human) $[45,46]$.

The partial amino acid sequence (104 aa from 202 aa, in total) inferred from the coding region within fragment 3 (Fig. 1c), showed no change in all the species analyzed, except for Gallus gallus (the outgroup species) where 13 aminoacids were modified. This conservation at the protein level is different from the scenario observed at the genomic level. We detected 8 transitions and 2 transversions when comparing the coding fragment between Homo sapiens and Felis catus. All these sequence variations correspond to synonymous or silent mutations. Considering these evidences, it is encouraging to think that the ongoing studies regarding the TWIST1 gene in Homo sapiens can be extrapolated to Felis catus.

The in silico analysis presented allowed the physical map of TWIST1 gene to several species: Felis catus chr A2q21.3, Canis familiaris chr 14, Homo sapiens chr 7p21.1, Pan troglodytes chr 7, Macaca mulatta chr 3, Mus musculus chr 12B2, Rattus norvegicus chr 6q16 and Bos taurus chr 4. The importance of gene mapping in genetic clinical studies is

\section{Homo sapiens TWIST1 gene (2188 bp)}

\begin{tabular}{|l|l|l|}
\hline $351 \mathrm{bp}$ & $609 \mathrm{bp}$ & \\
\hline
\end{tabular}

\section{Felis catus isolated sequence $(960 \mathrm{bp})$}

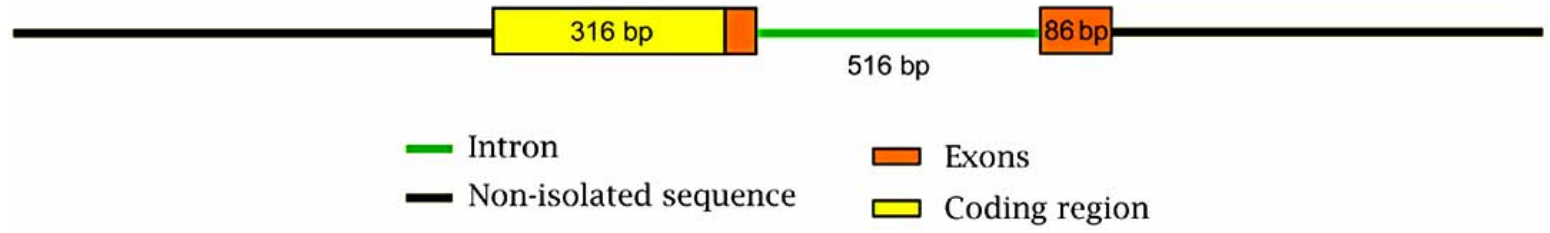

Fig. (5). Schematic representation of the Homo sapiens TWIST1 gene and the orthologous gene sequence isolated in the present work from Felis catus (960 bp in total). We can observe that we have isolated 358 bp of exon 1 (including 316 bp of the coding region), 516 bp of the intron and $86 \mathrm{bp}$ of the exon 2 . 
well known for diagnosis purposes. In this paper we present a new approach that can be used to in silico gene map, and can use several tools that result from the cat and canine genomes sequencing efforts, that is, sequence data and radiation hybrid maps.

\section{CONCLUDING REMARKS}

We believe that this investigation is the first to isolate the partial sequence of the TWIST1 gene in the Felis catus and to perform comparative analysis between this oncogene in cat with other species, namely Homo sapiens. We observed that, regarding this gene, there is a higher similarity between cat and man than between man and other widely used animal models such as rat or mouse, and that TWIST1 maps to the q21.3 band from cat chromosome A2. This work gives the first insights regarding the TWIST1 gene in Felis catus, so in the future, we may contribute to the study of the molecular mechanisms affecting its expression profile in cat tumor cells.

\section{ACKNOWLEDGEMENTS}

We thank to Portuguese Foundation for Science and Technology (FCT) for funding our work, namely project POCI/CVT/62940/2004 and a PhD grant SFRH/BD/31754/ 2006.

\section{SUPPLEMENTARY MATERIAL}

Supplementary material is available on the publishers Web site along with the published article.

\section{REFERENCES}

[1] Nusslein-Volhard, C.; Wieschaus, E.; Kluding, H. Mutations affecting the pattern of the larval cuticle in Drosophila melanogaster. 1. Zygotic loci on the 2nd chromosome. Roux's Arch. Dev. Biol., 1984, 193, 267-282.

[2] Simpson, P. Maternal-zygotic gene interactions of the dorsoventral pattern in Drosophila embryos. Genetics, 1983, 105, 615-632.

[3] Thisse, B.; Messal, M.; Perrin-Schmitt, F. The twist gene: isolation of a Drosophila zygotic gene necessary for the establishment of dorsoventral pattern. Nucleic Acids Res., 1987, 15, 3439-3453.

[4] Rose, C.S.; Malcolm, S. A TWIST in development. Trends Genet., 1997, 13, 384-387.

[5] Wang, S.M.; Coljee, V.W.; Pignolo, R.J.; Rotenberg, M.O.; Cristofalo, V.J.; Sierra, F. Cloning of the human twist gene: its expression is retained in adult mesodermally-derived tissues. Gene, 1997, 187, 83-92.

[6] Maestro, R.; Dei Tos, A.P.; Hamamori, Y.; Krasnokutsky, S.; Sartorelli, V.; Kedes, L.; Doglioni, C.; Beach, D.H.; Hannon, G.J. Twist is a potential oncogene that inhibits apoptosis. Genes Dev., 1999, 13, 2207-2217.

[7] Puisieux, A.; Valsesia-Wittmann, S.; Ansieau, S. A twist for survival and cancer progression. $\mathrm{Br}$. J. Cancer, 2006, 94, 13-17.

[8] van Doorn, R.; Dijkman, R.; Vermeer, M.H.; Out-Luiting, J.J.; van der Raaij-Helmer, E.M.; Willemze, R.; Tensen, C.P. Aberrant expression of the tyrosine kinase receptor EphA4 and the transcription factor twist in Sezary syndrome identified by gene expression analysis. Cancer Res., 2004, 64, 5578- 5586.

[9] Yang, J.; Mani, S.A.; Donaher, J.L.; Ramaswamy, S.; Itzykson, R.A.; Come, C.; Savagner, P.; Gitelman, I.; Richardson, A.; Weinberg, R.A. Twist, a master regulator of morphogenesis, plays an essential role in tumor metastasis. Cell, 2004, 117, 927-939.

[10] Krebs, I.; Weis, I.; Hudler, M.; Rommens, J.M.; Roth, H.; Scherer, S.W.; Tsui, L-C.; Füchtbauer, E-M.; Grzeschik, K-H.; Tsuji, K.; Kunz, J. Translocation breakpoint maps $5 \mathrm{~kb} 3^{\prime}$ from TWIST in a patient affected with Saethre-Chotzen syndrome. Hum. Mol. Genet., 1997, 6, 1079-1086.
[11] Yousfi, M.; Lasmoles, F.; Ghouzzi, V.E.; Marie, P.J. Twist haploinsufficiency in Saethre-Chotzen syndrome induces calvarial osteoblast apoptosis due to increased TNF $\alpha$ expression and caspase-2 activation. Hum. Mol. Genet., 2002, 1, 359-369.

[12] Gripp, K.W.; Stolle, C.A.; Celle, L.; McDonald-McGinn, D.M.; Whitaker, L.A.; Zackai, E.H. TWIST gene mutation in a patient with radial aplasia and craniosynostosis: further evidence for heterogeneity of Baller-Gerold syndrome. Am. J. Med. Genet., 1999, $82,170-176$.

[13] Entz-Werle, N.; Stoetzel, C.; Berard-Marec, P.; Kalifa, C.; Brugiere, L.; Pacquement, H.; Schmitt, C.; Tabone, M.D.; Gentet, J.C.; Quillet, R.; Oudet, P.; Lutz, P.; Babin-Boilletot, A.; Gaub, M.P.; Perrin-Schmitt, F. Frequent genomic abnormalities at TWIST in human pediatric osteosarcomas. Int. J. Cancer, 2005, 117, 349355.

[14] Sahlin, P.; Windh, P.; Lauritzen, C.; Emanuelsson, M.; Grönberg, H.; Stenman, G. Women with Saethre-Chotzen syndrome are at increased risk of breast cancer. Genes Chromosomes Cancer, 2007, 46, 656-660.

[15] Hoek, K.; Rimm, D.L.; Williams, K.R.; Zhao, H.; Ariyan, S.; Lin, A.; Kluger, H.M.; Berger, A.J.; Cheng, E.; Trombetta, E.S.; Wu, T.; Niinobe, M.; Yoshikawa, K.; Hannigan, G.E.; Halaban, R. Expression profiling reveals novel pathways in the transformation of melanocytes to melanomas. Cancer Res., 2004, 64, 5270-5282.

[16] Kwok, W.K.; Ling, M.T.; Lee, T.W.; Lau, T.C.; Zhou, C.; Zhang, X.; Chua, C.W.; Chan, K.W.; Chan, F.L.; Glackin, C.; Wong, Y.C.; Wang, X. Up-regulation of TWIST in prostate cancer and its implication as a therapeutic target. Cancer Res., 2005, 65, 5153-5162.

[17] Martin, T.A.; Goyal, A.; Watkins, G.; Jiang, W.G. Expression of the transcription factors snail, slug, and twist and their clinical significance in human breast cancer. Ann. Surg. Oncol., 2005, 12, 488-496.

[18] Rosivatz, E.; Becker, I.; Specht, K.; Fricke, E.; Luber, B.; Busch, R.; Hofler, H.; Becker, K.F. Differential expression of the epithelial-mesenchymal transition regulators snail, SIP1, and twist in gastric cancer. Am. J. Pathol., 2002, 161, 1881-1891.

[19] Vernon, A.E.; LaBonne, C. Tumor metastasis: a new twist on epithelial-mesenchymal transitions. Curr. Biol., 2004, 14, 719-721. Watanabe, O.; Imamura, H.; Shimizu, T.; Kinoshita, J.; Okabe, T.; Hirano, A.; Yoshimatsu, K.; Konno, S.; Aiba, M.; Ogawa, K. Expression of twist and wnt in human breast cancer. Anticancer Res., 2004, 24, 3851-3856.

[21] Hopwood, N.D.; Pluck, A.; Gurdon, J.B. Xenopus twist is expressed in response to induction in the mesoderm and the neural crest. Cell, 1989, 59, 893-903.

[22] Wolf, C.; Thisse, C.; Stoetzel, C.; Thisse, B.; Gerlinger, P.; PerrinSchmitt, F. The M-twist gene of Mus is expressed in subsets of mesodermal cells and is closely related to the Xenopus X-twi and the Drosophila twist genes. Dev. Biol., 1991, 143, 363-373.

[23] Soto, J.G.; Nelson, B.H.; Weisblat, D.A. A leech homolog of twist: evidence for its inheritance as a maternal mRNA. Gene, 1997, 199, 31-37.

[24] Morin-Kensicki, E.M.; Eisen, J.S. Sclerotome development and peripheral nervous system segmentation in embryonic zebrafish. Development, 1997, 124, 159-167.

[25] Yasui, K.; Zhang, S.; Uemura, M.; Aizawa, S.; Ueki, T. Expression of a twist-related gene, Bbtwist, during the development of a lancelet species and its relation to cephalochordate anterior structures. Dev. Biol., 1998, 195, 49-59.

[26] Harfe, B.D.; Fire, A. Muscle and nerve-specific regulation of a novel NK-2 class homeodomain factor in Caenorhabditis elegans. Development, 1998, 125, 421-429.

[27] Spring, J.; Yanze, N.; Middel, A.M.; Stierwald, M.; Gröger, H.; Schmid, V. The mesoderm specification factor Twist in the life cycle of Jellyfish. Dev. Biol., 2000, 28, 363-375.

[28] Tavares, A.T.; Izpisua-Belmonte, J.C.; Rodriguez-Leon, J. Developmental expression of Chick twist and its regulation during limb patterning. Int. J. Dev. Biol., 2001, 45, 707-713.

[29] Tárraga, J.; Medina, I.; Arbiza, L.; Huerta-Cepas, J.; Gabaldón, T.; Dopazo, J.; Dopazo, H. Phylemon: a suite of web tools for molecular evolution, phylogenetics and phylogenomics. Nucleic Acids Res., 2007, 35, W38 - W42.

[30] Thompson, J.D.; Higgins, D.G.; Gibson, T.J. CLUSTAL W: Improving the sensitivity of progressive multiple sequence alignment through sequence weighting, position-specific gap penalties and weight matrix choice. Nucleic Acids Res., 1994, 22, 4673-4680. 
[31] Felsenstein, J.; Churchill, G.A. A Hidden Markov Model approach to variation among sites in rate of evolution. Mol. Biol. Evol., 1996, 13, 93-104.

[32] Tamura, K.; Dudley, J.; Nei, M.; Kumar, S. MEGA4: Molecular Evolutionary Genetics Analysis (MEGA) software version 4.0. Mol. Biol. Evol., 2007, 24, 1596-1599.

[33] Rice, P.; Longden, I.; Bleasby, A. EMBOSS: the European Molecular Biology Open Software Suite. Trends Genet., 2000, 16, 276-277.

[34] Nicholas, K.B.; Nicholas, H.B. Gendoc: a tool for editing and annotating multiple sequence alignments. Multiple Sequence Alignment Editor and Shading Utility. Version 2.0.001. Distributed by the authors. 1997

[35] Pontius, J.U.; O'Brien, S.J. Genome Annotation Resource Fields-GARFIELD: a genome browser for Felis catus. J. Hered., 2007, 98, 386-389.

[36] Pontius, J.U.; Mullikin, J.C.; Smith, D.R.; Agencourt Sequencing Team; Lindblad-Toh, K.; Gnerre, S.; Clamp, M.; Chang, J.; Stephens, R.; Neelam, B.; Volfovsky, N.; Schäffer, A.A.; Agarwala, R.; Narfström, K.; Murphy, W.J.; Giger, U.; Roca, A.L.; Antunes, A.; Menotti-Raymond, M.; Yuhki, N.; Pecon-Slattery, J.; Johnson, W.E.; Bourque, G.; Tesler, G.; NISC Comparative Sequencing Program; O'Brien, S.J. Initial sequence and comparative analysis of the cat genome. Genome Res., 2007, 17, 1675-1689.

[37] Murphy, W.J.; Davis, B.; David, V.A.; Agarwala, R.; Schäffer, A.A.; Wilkerson, A.J.P.; Neelam, B.; O'Brien, S.J.; MenottiRaymond, M. A 1.5-Mb-resolution radiation hybrid map of the cat genome and comparative analysis with the canine and human genomes. Genomics, 2007, 89, 189-196.
[38] Davis, B.W.; Raudsepp, T.; Pearks Wilkerson, A.J.; Agarwala, R.; Schäffer, A.A.; Houck, M.; Chowdhary, B.P.; Murphy, W.J. A high-resolution cat radiation hybrid and integrated FISH mapping resource for phylogenomic studies across Felidae. Genomics, 2009 , 93, 299-304.

[39] Breen, M.; Hitte, C.; Lorentzen, T.D.; Thomas, R.; Cadieu, E.; Sabacan, L.; Scott, A.; Evanno, G.; Parker, H.G.; Kirkness, E.F.; Hudson, R.; Guyon, R.; Mahairas, G.G.; Gelfenbeyn, B.; Fraser, C.M.; André, C.; Galibert, F.; Ostrander, E.A. An integrated 4249 marker FISH/RH map of the canine genome. BMC Genomics, 2004, 5, 65 doi:10.1186/1471-2164-5-65.

[40] Baptista, C.S.; Villagrasa, M.H.; Marinho, A.A. Standardised Bscan and A-scan echographic evaluation of spontaneous anterior uveal melanomas in the dog. Vet. J., 2006, 171, 322-330.

[41] Paoloni, M.; Khanna, C. Translation of new cancer treatments from pet dogs to humans. Nat. Rev. Cancer, 2008, 8, 147-156.

[42] Vail, D.M.; MacEwen, E.G. Spontaneously occurring tumors of companion animals as models for human cancer. Cancer Invest., 2000, 18, 781-792.

[43] Vanin, E.F. Processed pseudogenes: characteristics and evolution Ann. Rev. Genet., 1985, 19, 253-272.

[44] Zheng, D.; Zhang, Z.; Harrison, P.M.; Karro, J.; Carriero, N.; Gerstein, M. Integrated pseudogene annotation for human chromosome 22: Evidence for transcription. J. Mol. Biol., 2005, 349, 27-45.

[45] Murphy, W.J.; Stanyon, R.; O’Brien, S.J. Evolution of mammalian genome organization inferred from comparative gene mapping. Genome Biol., 2001, 2(6), reviews0005.1-0005.8.

[46] O’Brien, S.J.; Wienberg, J.; Lyons, L.A. Comparative genomics: lessons from cats. Trends Genet., 1997, 13, 393-399. 